\title{
CHROMATIC DISPERSION COMPENSATION IN EXISTING FIBER OPTIC TELECOMMUNICATION LINES WITH THE GROWING BIT RATES NEEDS OF DWDM SYSTEM
}

Tomasz Bobruk

Cellnex Telecom, Warsaw, Poland

Abstract. The article presents an analysis of the methods of chromatic dispersion compensation in the existing, already built fiber optic telecommunications lines, based on ITU G.652 A and B fibers with the constantly growing demand for bit rates in DWDM systems. Due to the enormous investment costs, it is impossible to replace the cables used with NZDSF, hence the chapter analyzes methods of improving the bandwidth without replacing all cables. Typical models of the optimization of chromatic dispersion in the existing lines are presented.

Keywords: chromatic dispersion, optical fiber dispersion, compensation, DWDM

\section{KOMPENSACJA DYSPERSJI CHROMATYCZNEJ W ISTNIEJĄCYCH ŚWIATEOWODOWYCH LINIACH TELEKOMUNIKACYJNYCH Z ROSNĄCYM ZAPOTRZEBOWANIEM PRZEPLYWNOŚCI W SYSTEMACH DWDM}

Streszczenie. W artykule przedstawiono problematyke kompensacji dyspersji chromatycznej wistniejacych, już wybudowanych świattowodowych liniach telekomunikacyjnych, opartych o włókna w standardzie ITU G.652 A i B z ciagle rosnacym zapotrzebowaniem na przeptywności w systemach DWDM. Ze względu na ogromne koszty inwestycyjne wymiana zastosowanych kabli na NZDSF jest niemożliwa, stąd w artykule analizowane sa sposoby poprawy pasma bez wymiany wszystkich kabli. Przedstawiono typowe modele procesu optymalizacji dyspersji chromatycznej w istniejacych liniach.

Słowa kluczowe: dyspersja chromatyczna, dyspersja światłowodowa, kompensacja, DWDM

\section{Introduction}

The publication concerns the existing DWDM telecommunications network with optical crossconnects (OXC), which has been developed for years by telecommunication operators based on single mode fiber on the ITU G.652 A and B standard. These networks are constantly expanded by adding new fiber optic lines based on the latest ITU G.652 D standards.

While the current development of the network consisting in increasing the transmission speed to $10 \mathrm{Gbit} / \mathrm{s}$ and increasing the number of optical channels was possible assuming the typical characteristics of single mode fibers (G.652), the use of new generation systems with a bit rate of $40 \mathrm{Gbit} / \mathrm{s}$ and the everincreasing demand for a wider bandwidth will require a detailed analysis and verification of the existing network resources, especially in terms of chromatic dispersion [6] and polarization dispersion which is non-linear and depends on the geometry of the fibers used $[2,7]$.

Optical transmission in DWDM systems is transmitted over sections of up to several hundred kilometers, there is a need to measure and compensate the chromatic dispersion, taking into account the fiber standards used in the network, in search of increasing the bandwidth to a specified level, with the minimum allowable additional attenuation $[4,9]$.

The main limitation is the existing infrastructure built on the basis of G.652 A and B fibers. These fibers have a relatively large dispersion. Replacing these cables with the newer NZDSF is not possible due to the enormous investment costs.

Another thing, NZDSF type fibers have lower dispersion than standard fibers, but some of them have a higher dispersion characteristic slope, which makes proper compensation of dispersion in long lines using DWDM technique a critical problem [6].

The publication explores ways to improve bandwidth without replacing all existing cables.

\section{Optical transmission systems}

\subsection{DWDM (Dense Wavelength Division Mulitplexing)}

The optical transmission system most often used in telecommunications is the DWDM system (Dense Wavelength Division Mulitplexing), which enables transmission with a total bit rate calculated in Tbit/s.
The DWDM system is the simultaneous introduction to the fiber of several dozen or several hundred optical signals, with wavelengths shifted between each other by $200 \mathrm{GHz}$ or a fraction of it $(100 \mathrm{GHz}, 50 \mathrm{GHz}, 25 \mathrm{GHz})$.

The first implemented DWDM systems are a simple point-topoint transmission multiplication. Transmitters with lasers of different wavelengths are placed at the beginning of the line. The signals are summed in a multiplexer connected to a single mode optical fiber. At the other end of the fiber optic line there is a demultiplexer that distributes the waves to different receivers. Between the nodes of this network, optical amplifiers are placed, significantly increasing the transmission range, and ADM devices (Add Drop Multiplexer), enabling the separation of one or more waves from the fiber for local customer. The amplifiers increase the ranges, but don't eliminate the distortion of the pulses caused by chromatic dispersion or polarization. The phenomenon of non-linearity causes inter-channel interference (FWM - Four Wave Mixing), which highly reduces the range or bit rate of channels [10].

The DWDM system uses the C and L optical bands in the $1530 \mathrm{~nm}$ to $1610 \mathrm{~nm}$ range [10].

\subsection{MetroDWDM (Metropolitan DWDM)}

Optical networks for urban agglomerations for which MetroDWDM systems (Metropolitan DWDM) have been developed are less demanding in terms of transmission range. The total bit rate of the system is over $2000 \mathrm{Gbit} / \mathrm{s}$. The essence of these systems is the use of DWDM wave multiplication in closed ring configuration, increased bit rate in relation to DWDM, the possibility of creating connections in a mesh configuration, smaller distances between nodes, greater variety of interfaces, flexible management system, quick reconfiguration for traffic management or connecting new customers to the network [10].

\section{Dispersion compensation and its application in telecommunications optical fiber lines}

\subsection{DCF-SMF}

The most popular method of chromatic dispersion compensation in telecommunications optical fiber lines is the use of a DC-SMF (Dispersion Compensating Single Mode Fiber) fiber. A fragment of such optical fiber is inserted into the existing line [3]. Fig. 1 shows a diagram of such a solution. 


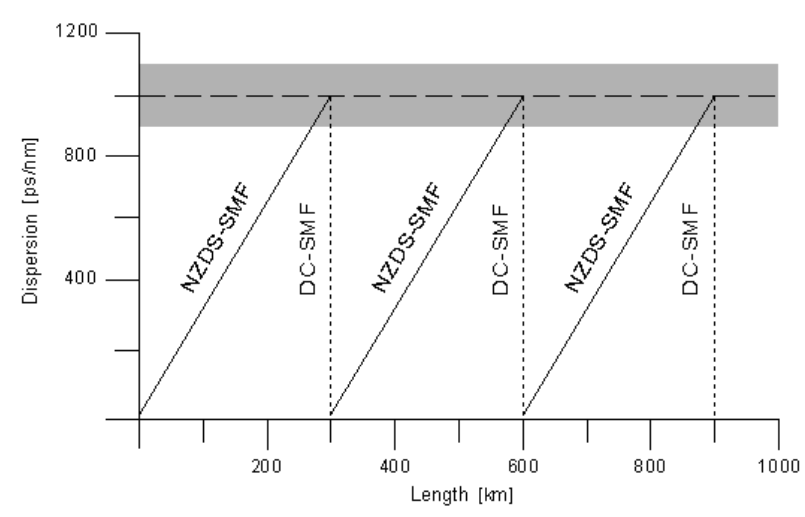

Fig. 1. Dispersion compensation of NZDS-SMF optical fiber with applied $D C-S M F[5]$

It turns out that for a line built of NZDS-SMF fibers, transmission with a speed of $10 \mathrm{Gbit} / \mathrm{s}$ can be transferred up to $360 \mathrm{~km}$. Introducing the $3 \mathrm{~km}$ section of the DC-SMF fiber to the line results in receiving an unexpanded pulse at the output.

On the other side, in DWDM systems based on DC-SMF lines, the simultaneous use of EDFA amplifiers is a limitation, because the compensation factor isn't a constant value and depends on the transmitted power level and the bit rate $[5,15]$.

\subsection{Fiber Bragg Grating}

Grating with a variable period are also perfect for dispersion compensation, which, due to their application, are also called for short DCG (Dispersion Compensating Gratings). Due to the uneven distribution of the grating, different wavelengths are reflected in different places, so they travel different paths and, consequently, each wavelength experiences a different exit delay:

$$
\tau(\lambda) \approx \frac{\left(\lambda_{0}-\lambda\right)}{\Delta \lambda_{\text {chirp }}} \cdot \frac{2 L_{g}}{v_{g}}
$$

where $\Delta \lambda_{\text {chirp }}=2 n_{\text {eff }} \Delta \Lambda_{\text {chirp }}$, and $l_{0}$ mid-wavelength of grating, $v_{g}$ average group speed of the light in the fiber.

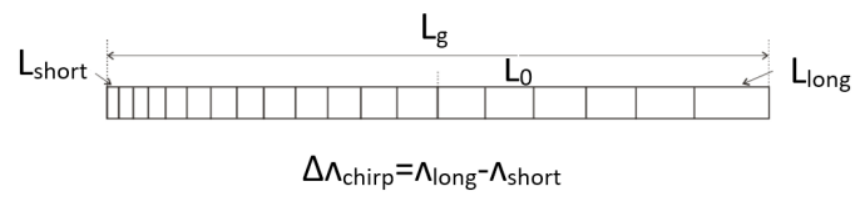

Fig. 2. Fiber Bragg Grating with variable period [8]

Fiber Bragg Graiting are used to create narrow- and wideband dispersion compensators and compensators for the slope of the dispersion characteristic. Such compensators are characterized by low losses and introduce relatively small delays. Therefore, they are perfect for use in long distance WDM and DWDM systems. Moreover, mesh adaptive compensators are manufactured, intended for use in undersea lines without multiplication, with a throughput of up to $40 \mathrm{Gbit} / \mathrm{s}[1,16]$.

The methods of installing the Fiber Bragg Grating in the system are presented in Fig. 3. As for compensating fibers (DCF), we can use grating compensators to precompensate, postcompensate or use them in any other available place for compensation of a single section.

On the basis of the Fiber Bragg Grating, in addition to the classic narrow-band compensators, there are also manufactured elements compensating the slope of the dispersion characteristic for WDM and DWDM systems, as well as adjustable compensators [12]. a)

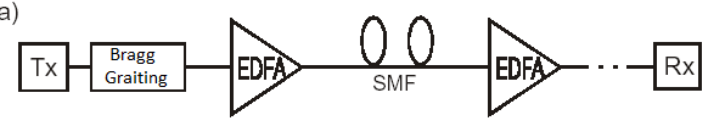

b)

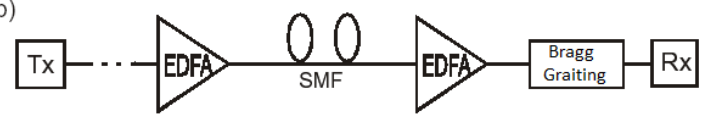

c)

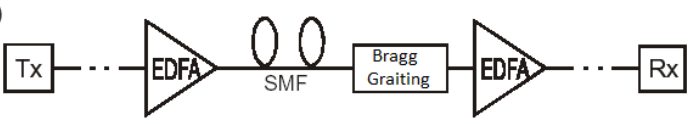

Fig. 3. Places of Fiber Bragg Grating installation as dispersion compensator: a) precompensation; b) post-compensation; c) compensation of one section [11]

The tunability of the compensator based on the Fiber Bragg Grating allows you to change the chromatic dispersion coefficient in the range from $940 \mathrm{ps} / \mathrm{nm}$ to even $8770 \mathrm{ps} / \mathrm{nm}$ [13].

\subsection{DC-PCF}

The methods of chromatic dispersion compensation presented they allow for optimal compensation in only one transmission window.

The use of photonic optical fibers with a double cladding structure (DC-PCF) allows to control dispersion in the full range of the transmission band, by modeling the wavelength at zero dispersion $\lambda_{0}$ and the dispersion slope coefficient [11].

Figure 4 shows the cross-section of a DC-PCF fiber with a double cladding and different coefficients of efficiency. The inner cladding has a hole diameter $\mathrm{d}_{1}$ and a distance between the centers of the holes $\Lambda_{1}$, and the outer hole diameter $d_{2}$ and a distance there between $\Lambda_{2} ; a_{1}$ the outer radius of the inner cladding, $a_{2}$ the inner radius of the outer cladding. The presented DC-PCF optical fiber has a central core, which are air holes in the inner cladding, and a second core, which is the area between $a_{1}$ and $a_{2}$. They come from here the parameters $R_{a}$ and $R_{n}$ :

$$
\begin{gathered}
R_{a}=\frac{a_{2}}{a_{1}} \\
R_{n}=\frac{n_{c l 2}-n_{c l 1}}{n_{c l 1}}
\end{gathered}
$$

where $n_{c l l}$ and $n_{c l 2}$ are the effective cladding coefficients, $R_{a}$ corresponds to the width of the second core, while $R_{n}$ is the wavelength dependent on the relative coefficient between the inner and outer cladding.

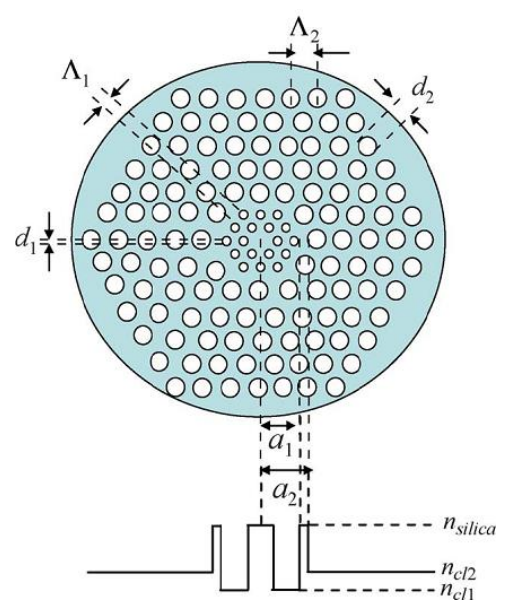

Fig. 4. DC-PCF fiber cross section and effective coefficient index profile [11] 
The first requirement when designing a dispersion compensating fiber is to match the slope of the characteristic for a SMF at a wavelength of $1550 \mathrm{~nm}$. Another variable taken into consideration is the wavelength value at zero dispersion $\lambda_{0}$ attenuating the dispersion insufficiency $\lambda_{0}$ at SMF. These two requirement lead to compensation - the dispersion of the DC-PCF fiber decreases as the wavelength increases.

That means, the dispersion characteristics in photonic optical fibers with small distances between holes depend on the distance between the centers of the holes and their size. When designing a DC-PCF fiber, a $1 \%$ change in the distance between the centers of the holes $\Lambda_{l}$ causes a $1 \%$ change in the zero dispersion length $\lambda_{0}$. It can be assumed that the poor quality of the surface of the air holes will cause dispersion and additional losses and multi-pass interference. Therefore, a more precise fabrication process would require an additional firing technique. Moreover, the improvement of the splicing technique, through the use of taper fibers, will be needed to reduce the loss of splices between DC-PCF and the standard SMF fiber [11].
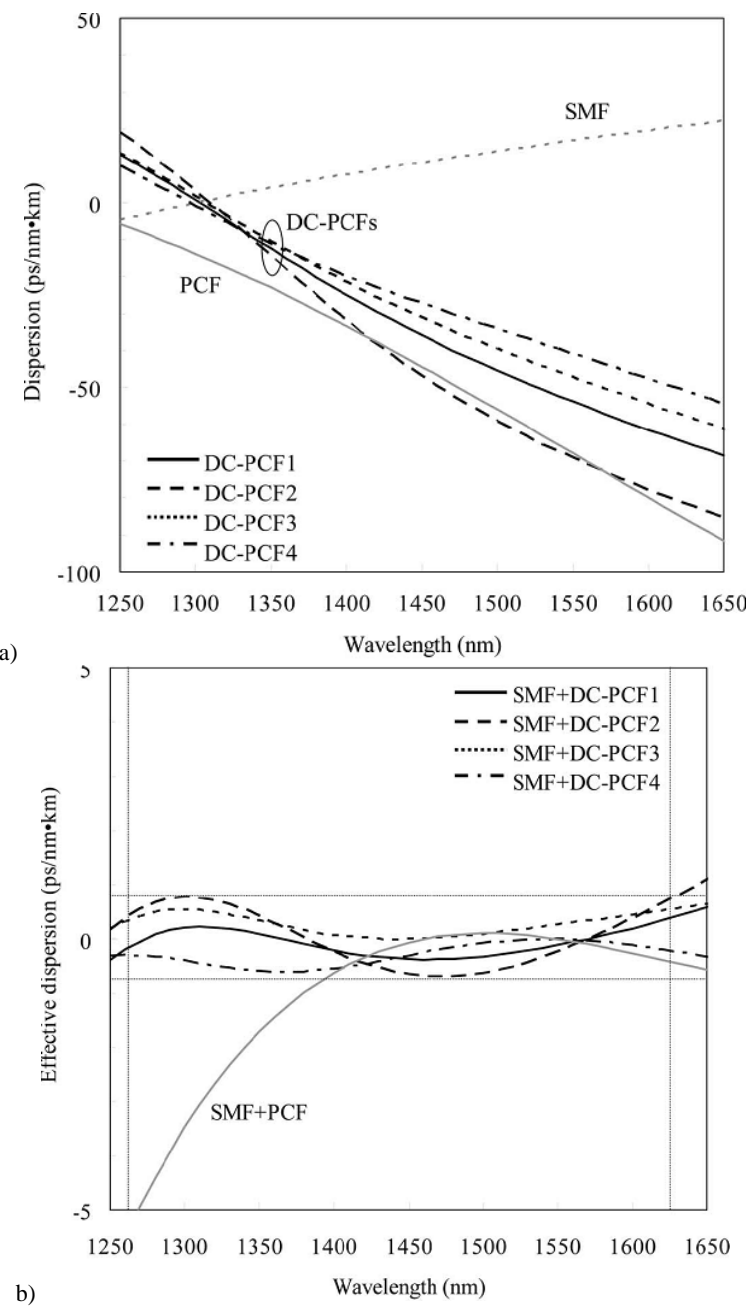

b)

Fig. 5. Characteristics of the designed DC-PCF fiber. (a) properties of the designed $D C-P C F$ fiber compared to conventional DCF and SMF fiber, (b) Effective dispersion of $S M F+D C-P C F$ and $S M F+P C F$ fiber [11]

Figure 5a shows the dispersion characteristics in the designed DC-PCF optical fiber. The figure also shows the dispersion in the PCF fiber (solid gray line). The dotted curve follows the dispersion in a conventional SMF fiber. Figure $5 \mathrm{~b}$ also shows the effective dispersion for the SMF + DC-PCF and SMF + PCF fiber. The SMF coefficient fiber length and optical fiber compensation result in even smaller changes in the effective dispersion in the all telecommunications band. Figure $5 \mathrm{~b}$ confirms that the design of the DC-PCF was achieved by efficient dispersion $\pm 0.8 \mathrm{ps} \cdot \mathrm{nm} \cdot \mathrm{km}$ in the all telecommunications band $[11,14]$.

\section{Optimization of the compensation process in telecommunications optical lines}

Typical possibilities of optimizing the chromatic dispersion compensation process in operator telecommunication lines are presented below.

\subsection{SMF line without compensation}

The first variant concerns the existing telecommunication line built on the basis of optical fibers in the G.652 A standard.

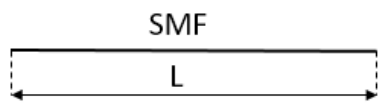

Fig. 6. SMF line

The attenuation of this line is given by the formula:

$$
A=\alpha \cdot L
$$

where $\alpha$ - attenuation of the SMF line [dB/km], $L$ - length of the SMF line $[\mathrm{km}]$,

while the total dispersion of the SMF line is:

$$
d=D \cdot L
$$

where $D$ - unit dispersion of the SMF line $[\mathrm{ps} / \mathrm{nm} \cdot \mathrm{km}]$.

\subsection{SMF line with DCF compensator}

In this model, a DCF optical fiber was used to compensate for the SMF line, which was wound on a drum and placed in a telecommunications node.

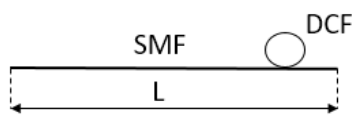

Fig. 7. SMF line with DCF compensator

The attenuation of such a line is:

$$
A=\alpha \cdot L+\alpha_{c} \cdot L_{c}
$$

where $\alpha_{c}$ - compensator attenuation $[\mathrm{dB} / \mathrm{km}], L_{c}-$ compensator length $[\mathrm{km}]$,

while the total dispersion of the line with the applied DCF compensator is:

$$
d=D \cdot L+D_{c} \cdot L_{c}
$$

where $D_{c}-$ unit dispersion of the compensator $[\mathrm{ps} / \mathrm{nm} \cdot \mathrm{km}]$

\subsection{SMF line with the SMF line section replaced with DCF cable}

In this model, the SMF line of $L-L_{c}$ length assumed the replacement of a section of the existing SMF cable with a DCF cable of $L_{c}$ length.

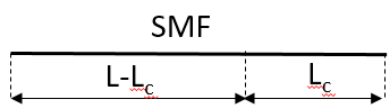

Fig. 8. SMF line with the SMF line section replaced with DCF cable

Then the attenuation of such a line will be:

$$
A=\alpha \cdot\left(L-L_{c}\right)+\alpha_{c} \cdot L_{c}
$$

and total line dispersion:

$$
d=D \cdot\left(L-L_{c}\right)+D_{c} \cdot L_{c}
$$




\subsection{SMF line with DCG compensator attached at the end of the line}

In this model, DCG was used to compensate for the dilution, which was placed at the end of the line.

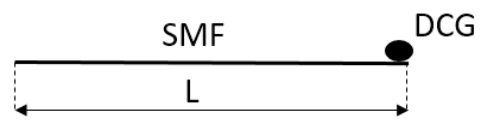

Fig. 9. SMF line with DCG compensator attached at the end of the line

The attenuation of such a line will be:

$$
A=\alpha \cdot L+A_{B}
$$

where $A_{B}-$ DCG attenuation [dB],

and the total line dispersion is:

$$
d=D \cdot L+d_{B}
$$

where $d_{B}$ denotes DCG dispersion [ps/nm].

The graph and the calculated values of $A$ and $d$ by $1550 \mathrm{~nm}$ for an exemplary 100 kilometer line are shown Fig. 10 and 11. The following values were adopted for the calculations $\alpha=0.2 \mathrm{~dB} / \mathrm{km}, \alpha_{c}=-0.5 \mathrm{~dB} / \mathrm{km}, D=17 \mathrm{ps} / \mathrm{nm} \cdot \mathrm{km}$, $D_{c}=-90 \mathrm{ps} / \mathrm{nm} \cdot \mathrm{km}, A_{B}=10 \mathrm{~dB}, d_{B}=-1670 \mathrm{ps} / \mathrm{nm}$.

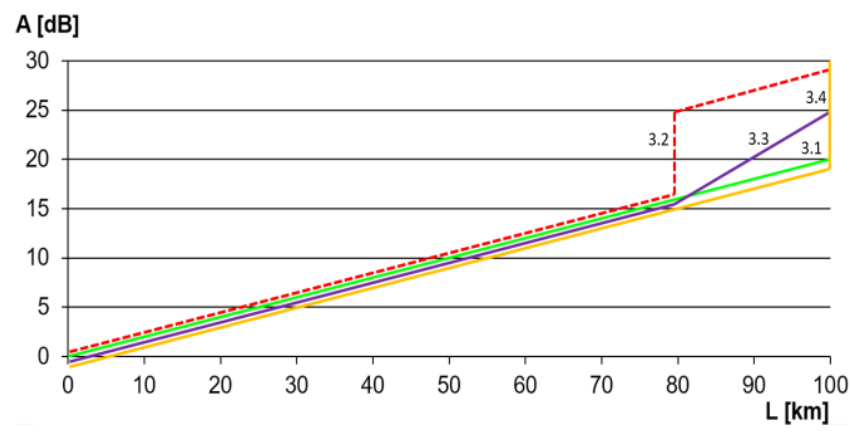

Fig. 10. Graph of the dependence of the attenuation on the length of the fiber optic line, taking into account the dispersion compensator

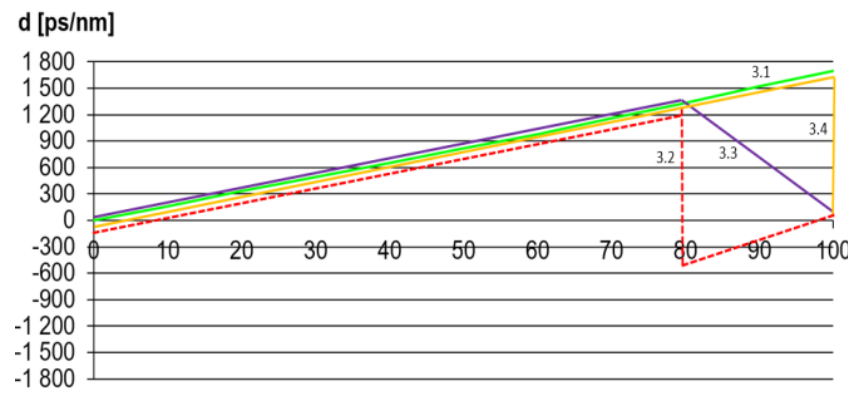

$\mathrm{L}[\mathrm{km}]$

Fig. 11. Graph of the dependence of the total line dispersion on the length of an optical fiber line, taking into account the dispersion compensator

\section{Conclusion}

The presented results of the analyzes show that using method 3.3 it is possible to obtain the lowest line attenuation, while from the point of view of the telecommunications network operator, taking into account the current expenditures, the best way to optimize the process of chromatic dispersion compensation in the existing optical fiber lines is the method presented in point 3.2. The DCF compensator, wound on the drum and placed in the node, at the current market prices of several thousand zlotys, guarantees effective compensation of dispersion to a level around $0 \mathrm{ps} / \mathrm{nm}$
The optimization method presented in point 3.3 , also allows to achieve good levels of compensation, but with slightly higher investment costs (the current level is $8-10$ thousand zlotys per kilometer).

Of course, presented methods of dispersion compensation, are not able to shape the dispersion characteristics of the line in the all available band, which is especially important in DWDM systems. They do not correct dispersion evenly, they only correct it for a specific wavelength (most often it is the "middle wavelength" for the $\mathrm{C}$ band, that is $1550 \mathrm{~nm}$ ), while the adjacent wavelengths will be overcompensated or insufficiently compensated [6].

In some optical fibers there is a 2-3 times difference in dispersion values for the C-band wavelengths. Thus, proper management of line dispersion is the process of balancing it with positive and negative dispersion along the length of the line over the entire spectral range of interest so that the total dispersion value is close to zero or within predetermined limits.

This means that it is necessary to precisely measure the total dispersion for each optical telecommunication line and select the compensation (for example DCF fiber length) in order to obtain a dispersion characteristic appropriate for a given telecommunications line in a wide range.

\section{References}

[1] Andreev V. et al.: Chromatic dispersion monitoring based on Bragg notch filter central frequency polyharmonic probing. Proc. SPIE 11146/2019, $111461 \mathrm{M}, 7-9$.

[2] Bo L. et al:: Optical frequency comb generation for DWDM transmission over 25- to 50-km standard single-mode fiber. Optical Engineering 57(1), 2018, $1-12$.

[3] Bobruk T., Wójcik W., Smolarz A.: Dispersion and its compensation in telecommunication optical fibers. Proc. SPIE 6608, 2007, 660814.

[4] Chorchos Ł., Turkiewicz J.: SSMF $1310 \mathrm{~nm}$ dispersion characteristic influence on the $400 \mathrm{Gbit} / \mathrm{s}$ and $1000 \mathrm{Gbit} / \mathrm{s}$ ethernet physical layer design, Proc. SPIE 10445, 2017, 104450E

[5] Drabik Z.: Procedura wyznaczania niepewności pomiaru dyspersji chromatycznej Laboratorium Badawczego OTO. OTO Lublin, Lublin 2000.

[6] Drabik Z., Koper Z.: Wyzwania dla sieci optycznej TPSA stawiane przez technikę transmisji 10Gbit/s. Researchgate 2003.

[7] Fischer G. et al.: Automatic polarization mode dispersion compensation in $40 \mathrm{~Gb} / \mathrm{s}$ optical transmission system. Ei.Uni-Paderborn, August 2016, 1-5.

[8] Hayami S., Mukasa K., Sugizaki R.: Dispersion-Managed Transmission Lines with Reverse-Dispersion Fiber. Furukawa Review 19, 2000, 6-8

[9] Huang Y., Yang H., Mao Y.: Design of linear photonic crystal fiber with allpositive/negative ultraflattened chromatic dispersion for the whole telecom band. Optical Engineering 60(7), 2021, 1-3.

[10] Kowalski A.: Modern optical networks and systems. Proc. SPIE 6608, 2007, 660811.

[11] Matsiu T., Nakajima K., Sankawa I.: Dispersion Compenastion Over All the Telecomunication Bands With Double-Cladding Photonic-Crystal Fiber. Lightwave Technology 25(3), 2007, 1-5.

[12] Nguyen H. et al.: Ultra-flattened chromatic dispersion in all-solid hybrid microstructured optical fibers for mid-infrared lightwave generation. Proc. SPIE 10902, 2019, 109021Q

[13] Perlicki K.: Systemy Transmisji Optycznej WDM. WKL, Warszawa 2007.

[14] Song P., Wang J., Zhou C.: High birefringence and near-zero dispersion photonic crystal fiber at the wavelength of $1.55 \mu \mathrm{m}$. Proc. SPIE 10255, 2017, 1025530

[15] Szymańska A.: Łacza światłowodowe - budżet mocy. Politechnika Warszawska, Ośrodek Kształcenia na Odległość OKNO, Warszawa 2018.

[16] http://www.teraxion.com (available 1.10.2021).

\section{M.Sc. Tomasz Bobruk}

e-mail: tomaszbobruk@gmail.com

Ph.D. student at the Lublin University of Technology. He professionally build fiber optic networks for telecommunications operators.

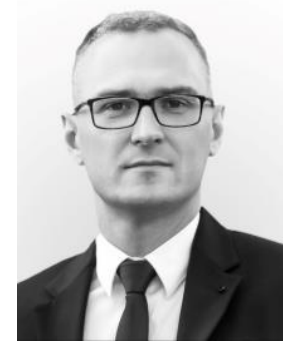

otrzymano/received: 5.11 .2021

przyjęto do drukulaccepted: 15.12.2021 